\title{
Accessibility helps persons $60+$ remain independent
}

\section{Opinion}

Electronics get smarter as more accessibility helps persons $60+$ remain independent. Electronics with accessibility built in can help an older adult in a variety of ways; as accessible technology allows the blind and low vision to read, the deaf and hard of hearing to hear better, and the physically disabled to gain access to their environment. What is Smart Technology? When we add a computer to an electronic device, it makes the device smarter. Smart technology is being built into all electronics and that is putting accessibility first, so that persons with disabilities can more easily use technology, no matter if they have low vision, are hard of hearing or physically disabled.

Accessibility can help you read the newspaper, a prescription bottle, or see your computer screen. Do you need help hearing your telephone, TV, doorbell, or other device, there are a variety devices with accessibility built in so you can hear it or see a flashing light. Accessibility can help with your mobility in order to travel safely, or ride up or down a staircase. There are many solutions to help you now which will allow you to remain independent, and improve your quality of life. According to the World Health Organization, there are over one billion people in the world with a disability and that is why technology is getting smarter with accessibility being built in. Take a tablet computer as an example; Apple, Android and Microsoft all have accessibility built into their products which can make using them much easier. Everybody benefits from more accessibility!

\section{About the author}

Patrick J Fischer believes that technology is the best way to improve the lives of the deaf, blind, and other disabled individuals. When he first entered the computer industry as a technician, he began
Volume 6 Issue 3 - 2017

\author{
Patrick J Fischer \\ Accessibility dot Net Publishing Company, USA
}

Correspondence: Patrick J Fischer, CEO Accessibility dot Net Inc, Post Office box 641948, Omaha NE 68I64, USA, Tel 402699-4357, Email www.Accessibility.Net

Received: March 04, 2017 | Published: March 8, 2017

volunteering to help disabled individuals learn how to use technology. As Fischer moved through several different jobs in the industry, he continued to help the disabled community. Through his company, eventually called Vision Helpers, he began dedicating his career to helping people with blindness or low vision. In 2002, he opened his first showroom in Omaha, Nebraska, which sold low-vision products. He expanded to another showroom in Des Moines, Iowa. Fischer has since closed the showrooms and now works directly with individuals, businesses, and doctors to help those in need.

\section{Acknowledgments}

None.

\section{Conflicts of interest}

The authors declare that there is no conflict of interest.

\section{Funding}

None. 